\title{
Evaluation of the mineral content of infant formulas consumed in Brazil
}

\author{
Sabrina Vieira da Silva, ${ }^{*}$ Paula Mattanna, ${ }^{*}$ Cezar Augusto Bizzi,† Neila Silvia Peireira dos Santos Richards, \\ and Juliano Smanioto Barin*1 \\ *Departamento de Tecnologia e Ciência dos Alimentos, and \\ †Departamento de Química, Universidade Federal de Santa Maria, 97105-900, Santa Maria, RS, Brazil
}

\section{ABSTRACT}

The mineral content of 10 commercially available milk-based infant formulas widely consumed in Brazil was investigated. The levels of elements $(\mathrm{Ca}, \mathrm{Cu}, \mathrm{Fe}$, $\mathrm{K}, \mathrm{Mg}, \mathrm{Mn}, \mathrm{Na}$, and $\mathrm{Zn}$ ) were determined by inductively coupled plasma optical emission spectrometry after microwave-assisted wet digestion. The results were compared with the producers' label declarations and levels proposed by the Codex Alimentarius and the Brazilian National Health Surveillance Agency. The obtained results were in good agreement with certified reference materials, and the relative standard deviation of the measurements was always below $10 \%$, with the exception of $\mathrm{Cu}$ (up to 14\%). A high degree of variation between the experimental and producers' data was found for trace elements among different brands, with differences as high as 41 and $68 \%$ for $\mathrm{Cu}$ and $\mathrm{Zn}$, respectively. The content of minerals in the starting formulas was in accordance with levels established by the Codex Alimentarius, with the exception of 1 brand that had a Zn level that was not in agreement with the Codex minimum value. Among follow-up formulas, 2 brands contained levels of $\mathrm{Ca}$ and $\mathrm{K}$ that were higher than the maximum established by Brazilian standards, and 1 brand contained less than the minimum value recommended for $\mathrm{Zn}$. The guidance upper levels have not been established in the Codex Alimentarius for follow-up formulas, and the maximum value has been established for only 2 of the analyzed minerals. This lack of a standard could be a problem; as shown in the present study, if the Brazilian standard is used, several formulas could be considered out of specification. Despite the limited number of samples evaluated in this work, the levels of some elements were out of specification and special attention by the Brazilian government on the content of minerals in infant formulas is needed. Key words: microwave-assisted wet digestion, infant nutrition, trace element, milk

Received October 14, 2012.

Accepted February 23, 2013.

${ }^{1}$ Corresponding author: juliano@ufsm.br

\section{INTRODUCTION}

Human milk is considered an optimal source of nutrients for infants and provides all of the nutritive elements for normal infant growth in a form that is suitable for digestion. When breast feeding is not possible, desirable, or sufficient, infant formulas are often used as substitutes for human milk and play an indispensable role in infant nutrition (Ruiz et al., 1996; Alles et al., 2004; Sola-Larrañaga and Navarro-Blasco, 2006). Infant formulas are described as breast-milk substitutes that are specially manufactured to satisfy the nutritional requirements of infants and are based on the composition of human milk, which is the ideal food for infants (Rodríguez Rodríguez et al., 2000; Alles et al., 2004). Among the nutrients available (e.g., protein, lipids, and carbohydrates) in infant formulas, trace and mineral elements are essential for biological processes and play a vital role in normal growth and development. Trace element requirements are critical during infancy and early childhood due to the very high growth rate of children, and insufficient mineral intake may lead to deficiencies that can impair body functioning (Brätter et al., 1998; Taylor et al., 2004; Zand et al., 2011). Industrially produced foods could represent an important part of the diet of many infants, and it is very important that such food contains sufficient amounts of minerals and trace elements.

The Codex Alimentarius (Codex) is a global food standards program that is jointly sponsored by the Food and Agricultural Organization (Rome, Italy) and World Health Organization (Geneva, Switzerland). Its goal is to establish standards for various foods that will ensure consumer safety and facilitate trade (MacLean et al., 2010). A revised standard (Codex standard 721981, revision 2007; Codex Alimentarius Commission, 2007) has been adopted for infant formula, which, in Brazil, is used during the first 6 mo of life (Ministry of Health, National Health Surveillance Agency, 2011a). The minimum and maximum nutrient levels for infant formulas established by Codex are important to ensure that the nutritional needs of all healthy infants will be met, while avoiding levels leading to high intake, which 
could produce adverse effects (MacLean et al., 2010). In 1987, the Codex Committee on Foods for Special Dietary Uses adopted a standard for follow-up formula, which is used in Brazil for infants from 6 to 12 mo of age (Codex standard 156-1987; Codex Alimentarius Commission, 1987; Ministry of Health, National Health Surveillance Agency, 2011b). Follow-up milk formula ensures a balanced intake of nutrients and is undoubtedly more suitable for infants than cow milk because follow-up formula provides a lower intake of proteins and saturated fats and a higher concentration of PUFA, iron, and zinc than cow milk (Riva et al., 2007).

According to the Codex Alimentarius, the term infant formula is used for products designed for infants during the first months of life until the introduction of appropriate complementary feeding (at no later than 12 mo of age; Codex Alimentarius Commission, 2007). Follow-up formula is the term used for products for infants aged 6 mo and older and for young children (persons from the ages of 12 to 36 mo; Codex Alimentarius Commission, 1987). However, the Codex does not establish a specific term for the formulations used exclusively for infants less than 6 mo of age that are currently commercialized in Brazil. Thus, the terms starting and follow-up will be used for infant formulas used from 0 to 6 mo of age and from 6 to 12 mo of age, respectively, to avoid using different terms for the same formula.

Because starting and follow-up formulas are the major sources of nutrients during the first months of life, several authors have studied their quality to ensure adequate infant health (Hamill et al., 1989; Richmond et al., 1993; Guo et al., 1996; Ruiz et al. 1996; Bermejo et al., 2000; Hua et al., 2000; Krachler and Rossipal, 2000; Ikem et al., 2002; Sola-Larrañaga and NavarroBlasco, 2006; Al Khalifa and Ahmad, 2010; Lesniewicz et al. 2010; MacLean et al., 2010). However, only one study (De Castro et al., 2010) related to the mineral content of infant formulas consumed in Brazil has been published. Moreover, that work included only results for $\mathrm{Pb}, \mathrm{Cd}, \mathrm{Ca}$, and $\mathrm{Zn}$. Thus, the purpose of the present study was to determine the levels of essential elements $(\mathrm{Ca}, \mathrm{Cu}, \mathrm{Fe}, \mathrm{K}, \mathrm{Mg}, \mathrm{Mn}, \mathrm{Na}$, and $\mathrm{Zn}$ ) in the 10 most-consumed starting and follow-up formulas in Brazil and to compare the results with producer label declaration as well as the levels proposed by the Codex Alimentarius (Codex Alimentarius Commission, 1987, 2007) and Brazilian standards (Ministry of Health, National Health Surveillance Agency, 2011a,b). In addition, microwave-assisted digestion with diluted acids was used as a green sample preparation procedure for further simultaneous determination of elements by inductively coupled plasma optical emission spectrometry (ICP OES).

\section{MATERIALS AND METHODS}

\section{Samples}

Ten commercial starting and follow-up formulas that are widely accepted and consumed in Brazil were investigated. Formulas in powdered form were purchased in local supermarkets between late 2010 and early 2011. The starting formulas purchased were Nan Pro 1 (Nestlé Brasil Ltda., São Paulo, Brazil), Nestogeno 1 (Nestlé Brasil Ltda.), Aptamil 1 (Danone Brasil, São Paulo, Brazil), Milupa 1 (Danone Brasil), and Similac Advance 1 (Abbott Laboratórios do Brasil Ltda., São Paulo, Brazil). The follow-up formulas purchased were Nan Pro 2 (Nestlé Brasil Ltda.), Nestogeno 2 (Nestlé Brasil Ltda.), Aptamil 2 (Danone Brasil), Milupa 2 (Danone Brasil), and Similac Advance 2 (Abbott Laboratórios do Brasil Ltda.). Samples were coded with different letters for each producer. The numbers 1 and 2 were used for starting and follow-up formulas, respectively. A detailed description of the characteristics of the analyzed infant formulas is presented in Table 1.

\section{Instrumentation}

Samples were dried at $60^{\circ} \mathrm{C}$ in an oven (model 400/2ND; Nova Ética, Vargem Grande Paulista, SP, Brazil) before digestion and were weighed with an analytical balance (model AY 220; maximum: 220 g, $0.1 \mathrm{mg}$ of resolution; Shimadzu Corp., Kyoto, Japan). A microwave oven (Multiwave 3000 microwave sample preparation system; Anton Paar GmbH, Graz, Austria) equipped with 8 high-pressure quartz vessels (internal volume of $80 \mathrm{~mL}$, maximum operational temperature and pressure of $280^{\circ} \mathrm{C}$ and $8 \mathrm{MPa}$, respectively) was used in the experiments. Elements were determined by ICP OES using an axial view configuration spectrometer (Spectro Ciros CCD; Spectro Analytical Instruments GmbH \& Co. KG, Kleve, Germany) with a cross-flow nebulizer coupled to a Scott double-pass-type nebulization chamber. The plasma operating conditions and selected wavelengths were used as recommended by the instrument manufacturer (Spectro Analytical Instruments GmbH \& Co. KG, 2003) and are listed in Table 2.

\section{Reagents and Standards}

Distilled-deionized water (Milli-Q; $18.2 \mathrm{M} \Omega \cdot \mathrm{cm}$; Millipore Corp., Billerica, MA) and analytical-grade nitric acid (Merck KGaA, Darmstadt, Germany) were used to prepare samples and standards. Metal determination by ICP OES was performed with external calibration using analytical solutions ranging from 1.0 to $100 \mu \mathrm{g} / \mathrm{L}$ 
Table 1. Characteristics of the investigated starting and follow-up formulas

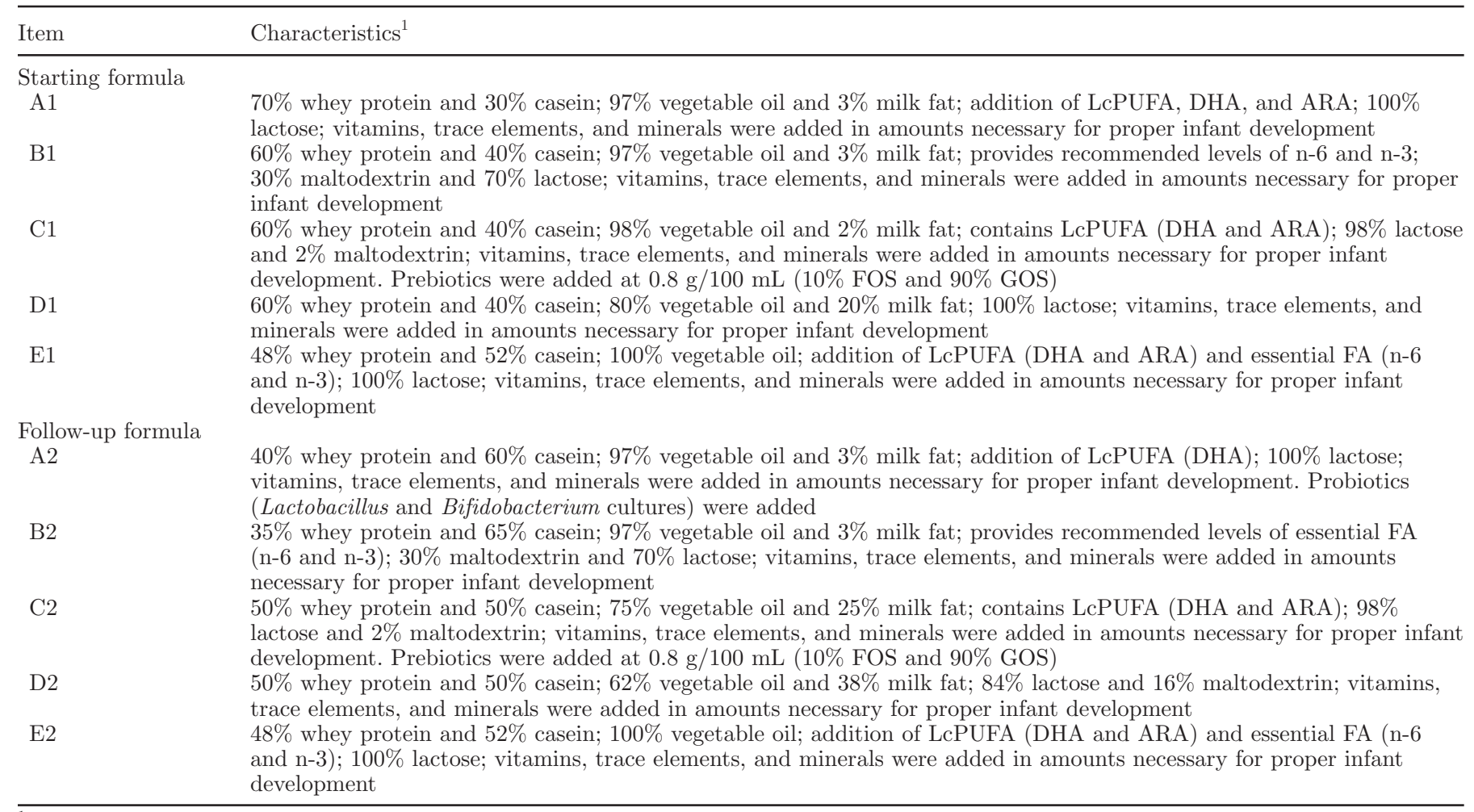

${ }^{1}$ LcPUFA = long-chain PUFA; DHA = docosahexaenoic acid; ARA = arachidonic acid; n- $6=$ linoleic acid; $\mathrm{n}-3=\alpha$-linolenic acid; FOS = fructooligosaccharide; GOS = galactooligosaccharide.

that were prepared in $0.7 \mathrm{~mol} / \mathrm{L} \mathrm{HNO}_{3}$ by appropriate dilution of the multi-element stock solution (SCP33MS; SCP Science, Baie D'Urfé, QC, Canada). Glass and quartz material were soaked in $1.4 \mathrm{~mol} / \mathrm{L} \mathrm{HNO}_{3}$ for $24 \mathrm{~h}$ and further washed with water before use. Argon (99.996\%; White Martins Praxair, São Paulo, SP, Brazil) was used for ICP OES determination for plasma generation and nebulization and as an auxiliary gas. Oxygen (99.9991\%; White Martins Praxair) was used as a reagent in digestions performed under oxygen pressure, using safety conditions, as recommended by the microwave oven manufacturer (Anton Paar GmbH, 2003). Accuracy was evaluated using certified reference materials (CRM) of skim milk powder (BCR 151; Community Bureau of Reference, Brussels, Belgium) and of nonfat milk powder (SRM NIST 1549; National Institute of Standards and Technology, Gaithersburg, MD).

\section{Microwave-Assisted Acid Digestion and ICP OES Determination}

Samples were digested according to the procedure described previously (Bizzi et al., 2011). Samples ( 400 $\mathrm{mg}$ ) were transferred to quartz vessels, and $6 \mathrm{~mL}$ of 3 mol/L $\mathrm{HNO}_{3}$ was added. After closing and capping the rotor, the vessels were pressurized with $0.75 \mathrm{MPa}$ bar of oxygen using the valve originally designed for pressure release after conventional acid sample digestion. Then, the rotor was placed inside the oven, and the microwave-heating program was started by applying (1) 1,000 W, increasing over $5 \mathrm{~min}$; (2) 1,000 W for $10 \mathrm{~min}$; and (3) $0 \mathrm{~W}$ for $20 \mathrm{~min}$ (cooling step). Af-

Table 2. Operational parameters for elemental determination by inductively coupled plasma optical emission spectrometry (ICP OES)

\begin{tabular}{lc}
\hline Parameter $^{1}$ & ICP OES \\
\hline Radio-frequency power (W) & 1,600 \\
Plasma gas flow rate (L/min) & 14.0 \\
Auxiliary gas flow rate (L/min) & 1.0 \\
Nebulizer gas flow rate (L/min) & 0.85 \\
Spray chamber & Double pass, Scott type \\
Nebulizer & Cross-flow \\
Observation view & Axial \\
Analyte emission line (nm) & \\
Ca (II) & 393.366 \\
Cu (I) & 324.752 \\
Fe (I) & 238.204 \\
K (I) & 766.490 \\
$\mathrm{Mg}(\mathrm{I})$ & 285.213 \\
$\mathrm{Mn}$ (II) & 257.610 \\
$\mathrm{Na}$ (I) & 589.592 \\
$\mathrm{Zn}(\mathrm{I})$ & 213.857 \\
\hline
\end{tabular}

${ }^{1} \mathrm{I}=$ atomic emission line; $\mathrm{II}=$ ion emission line. 
Table 3. Results obtained for the evaluated elements ( $\mathrm{Ca}, \mathrm{Cu}, \mathrm{Fe}, \mathrm{K}, \mathrm{Mg}, \mathrm{Mn}, \mathrm{Na}$, and $\mathrm{Zn} ; \mathrm{mg} / 100 \mathrm{~g}$ ) in the infant formulas studied (mean \pm $\mathrm{SD} ; \mathrm{n}=3$ )

\begin{tabular}{|c|c|c|c|c|c|c|c|c|}
\hline Sample & $\mathrm{Ca}$ & $\mathrm{Cu}^{1}$ & $\mathrm{Fe}$ & $\mathrm{K}$ & $\mathrm{Mg}$ & $\mathrm{Mn}^{1}$ & $\mathrm{Na}$ & $\mathrm{Zn}$ \\
\hline A1 & $317 \pm 10$ & $316 \pm 26$ & $6.50 \pm 0.44$ & $456 \pm 10$ & $35.0 \pm 1.5$ & $51.6 \pm 2.8$ & $122 \pm 10$ & $4.26 \pm 0.26$ \\
\hline B1 & $517 \pm 13$ & $307 \pm 10$ & $6.68 \pm 0.40$ & $678 \pm 18$ & $43.2 \pm 0.3$ & $34.0 \pm 0.5$ & $192 \pm 17$ & $4.03 \pm 0.14$ \\
\hline C1 & $432 \pm 11$ & $345 \pm 39$ & $5.32 \pm 0.13$ & $396 \pm 16$ & $38.1 \pm 1.2$ & $63.5 \pm 1.7$ & $112 \pm 7$ & $2.59 \pm 0.14$ \\
\hline D1 & $426 \pm 18$ & $274 \pm 45$ & $5.37 \pm 0.30$ & $456 \pm 34$ & $38.5 \pm 0.4$ & $57.3 \pm 1.1$ & $140 \pm 8$ & $1.25 \pm 0.12$ \\
\hline E1 & $547 \pm 37$ & $322 \pm 30$ & $2.69 \pm 0.11$ & $660 \pm 17$ & $38.2 \pm 0.5$ & $37.4 \pm 2.0$ & $136 \pm 5$ & $4.01 \pm 0.13$ \\
\hline A 2 & $616 \pm 34$ & $476 \pm 27$ & $7.22 \pm 0.11$ & $679 \pm 19$ & $44.4 \pm 0.6$ & $34.1 \pm 1.3$ & $190 \pm 17$ & $5.37 \pm 0.34$ \\
\hline $\mathrm{B} 2$ & $784 \pm 24$ & $514 \pm 37$ & $7.63 \pm 0.13$ & $977 \pm 37$ & $62.9 \pm 0.7$ & $33.4 \pm 0.9$ & $283 \pm 9$ & $6.08 \pm 0.32$ \\
\hline $\mathrm{C} 2$ & $637 \pm 18$ & $165 \pm 31$ & $6.69 \pm 0.36$ & $778 \pm 13$ & $60.0 \pm 0.8$ & $50.8 \pm 0.7$ & $227 \pm 6$ & $2.23 \pm 0.10$ \\
\hline D2 & $614 \pm 20$ & $183 \pm 41$ & $7.44 \pm 0.10$ & $606 \pm 13$ & $46.1 \pm 0.3$ & $60.6 \pm 1.8$ & $209 \pm 7$ & $3.32 \pm 0.11$ \\
\hline $\mathrm{E} 2$ & $552 \pm 42$ & $494 \pm 23$ & $8.53 \pm 0.16$ & $723 \pm 33$ & $38.3 \pm 0.4$ & $52.0 \pm 0.9$ & $148 \pm 9$ & $4.89 \pm 0.11$ \\
\hline
\end{tabular}

${ }^{1}$ Results are in micrograms per $100 \mathrm{~g}$.

ter digestion, the pressure in each vessel was carefully released. The resulting solutions were transferred to 30-mL polypropylene vials and diluted up to the mark with water. Digestion vessels were cleaned with $6 \mathrm{~mL}$ of concentrated $\mathrm{HNO}_{3}$ in the microwave oven at 1,000 W for $10 \mathrm{~min}$ and $0 \mathrm{~W}$ for $20 \mathrm{~min}$ for cooling.

\section{RESULTS AND DISCUSSION}

Because infant formulas are similar to milk powder, the accuracy of the testing procedure was verified by determining the elements in CRM of skim milk powder and nonfat milk powder (BCR 151, Community Bureau of Reference; SRM NIST 1549, National Institute of Standards and Technology; results not shown). The results obtained for $\mathrm{Ca}, \mathrm{Cu}, \mathrm{Fe}, \mathrm{K}, \mathrm{Mg}, \mathrm{Mn}, \mathrm{Na}$, and Zn for both CRM were in good agreement (better than 93\%) with the certified values (Student's $t$-test, $P>$ 0.05). The precision of the CRM measurements was evaluated in 3 independent samples. The relative standard deviations were lower than $10 \%$, with the exception of $\mathrm{Cu}$ (up to 14\%). This analytical variability is similar to that observed by MacLean et al. $(2010 ; 13 \%)$ for $\mathrm{Cu}$ determination in some infant formulas.

The results obtained for the evaluated formulas are shown in Table 3. The elements $\mathrm{Ca}$ and $\mathrm{K}$ had the highest concentrations, ranging from 317 (sample A1) to 784 (sample B2) mg/100 g of formula powder. The formula E1 contained the lowest amount of Fe (2.69 $\mathrm{mg} / 100 \mathrm{~g}$ ), whereas the largest Fe content was observed in sample E2 $(8.53 \mathrm{mg} / 100 \mathrm{~g})$. The $\mathrm{Zn}$ and $\mathrm{Na}$ concentrations ranged from 1.25 (sample D1) to 6.08 (sample B2) and 112.1 (sample C1) to 283 (sample C2) $\mathrm{mg} / 100 \mathrm{~g}$, respectively. The $\mathrm{Mg}$ concentrations ranged from 35.0 (sample A1) to 62.9 (sample B2) mg/100 g. The lowest contents were observed for the elements $\mathrm{Cu}$ and $\mathrm{Mn}$. The $\mathrm{Cu}$ concentration varied from 165 (sample C2) to 514 (sample B2) $\mu \mathrm{g} / 100 \mathrm{~g}$, whereas the Mn content varied from 33.4 (sample B2) to 63.5 (sample C1) $\mu \mathrm{g} / 100 \mathrm{~g}$.
The experimentally determined mineral contents were compared with the data reported on the labels by the producers (Figure 1). With the exception of sample A1, the Ca content in the formulas was higher than that declared on the label. In general, the difference between the labeled and determined values was less than $11 \%$, but for formulas E1 and E2, the difference reached 37 and $28 \%$, respectively. By contrast, the Fe content was lower than the labeled value, with the exception of samples A1 and B1, which had higher Fe contents than the labeled content. The greatest difference between the labeled and determined value was observed for sample E1 (23\%). This difference was less than $13 \%$ for the other formulas. For $\mathrm{K}, \mathrm{Mg}$, and $\mathrm{Na}$, the maximum difference reached 12 (sample E2), 23 (sample E1), and $26 \%$ (sample D1), respectively.

Nevertheless, the most significant difference between the labeled and experimental values was observed for trace elements $(\mathrm{Cu}, \mathrm{Mn}$, and $\mathrm{Zn})$. For $\mathrm{Cu}$, differences of 39,41 , and $37 \%$ were observed for formulas C2, D2, and E2, respectively. For Zn, differences as high as 68 and $49 \%$ were observed for formulas D1 and C2, respectively, whereas a difference of $73 \%$ was observed for $\mathrm{Mn}$ in formula E2. A similar phenomenon was reported by Lesniewicz et al. (2010), who observed that the experimentally determined values of $\mathrm{Mn}$ in Polish infant formulas were 3 times higher than the declared values. The large differences that were observed for $\mathrm{Cu}$, $\mathrm{Mn}$, and $\mathrm{Zn}$ could be due to the smaller amounts of these elements in formulas; these small values could be susceptible to large variations in the content of these elements in the raw materials. According to MacLean et al. (2010), Mn can be specifically added during the production of milk-based infant formulas or introduced in the products in small amounts by some of the calcium salts and by ferrous sulfate, which could lead to variations in the final composition. The same authors reported that the majority of the $\mathrm{Cu}$ in infant formula is added through the trace element premix during the manufacturing process, but the protein sources (e.g., 

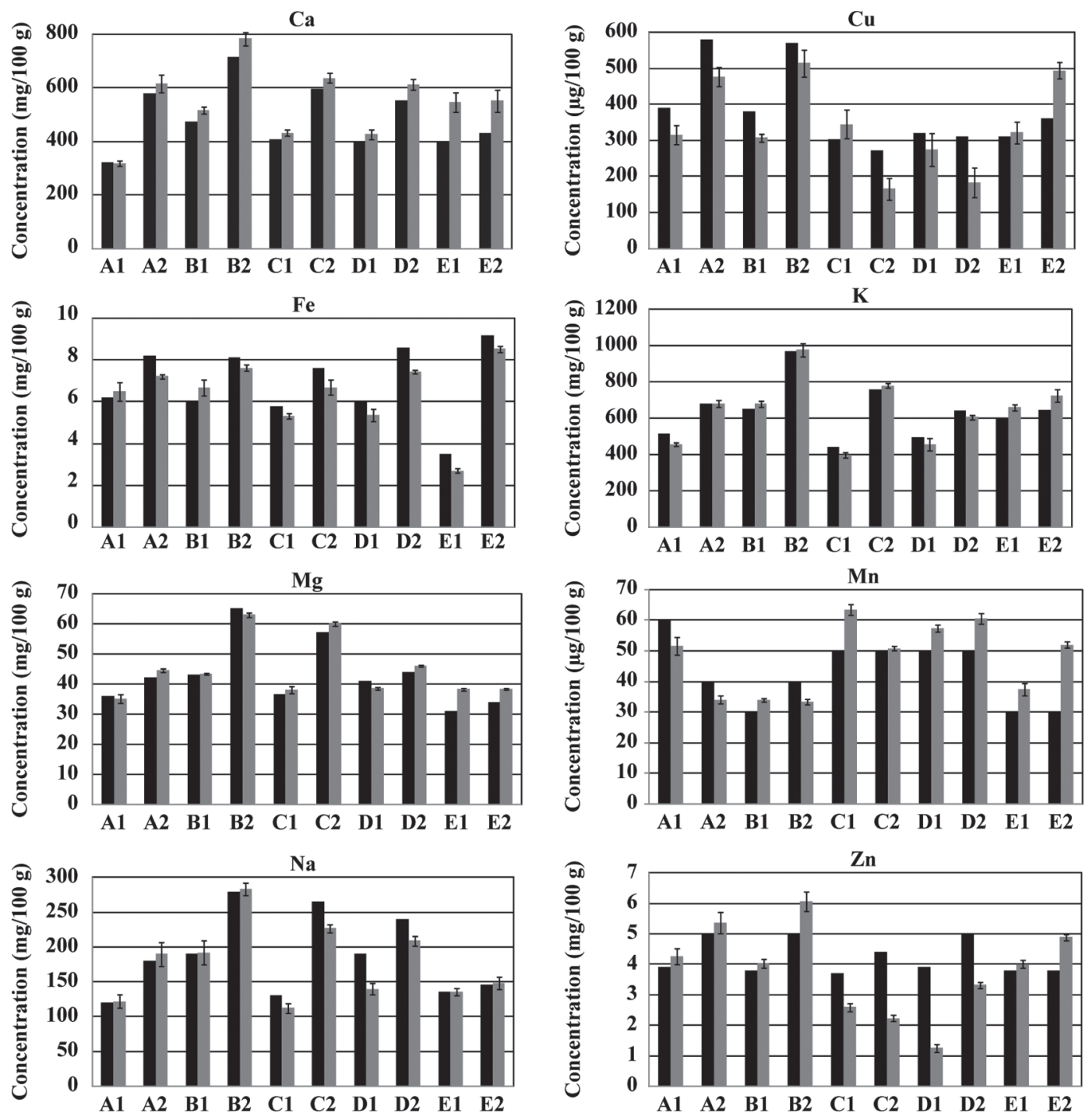

Figure 1. Comparison of the obtained results for elements (gray bars) with the values declared by the infant formula producers (black bars). The standard deviation is indicated by the error bars.

nonfat milk protein, whey protein concentrates, and soy protein isolates) variably contribute to the $\mathrm{Cu}$ level of infant formulas and could explain the behavior of this element in the formulas studied in their work. However, this variation is of concern due to the important role of these elements in infant metabolism (Kobla and Volpe, 2000).

A Student's $t$-test was also used for comparison between declared and experimental data for each element (5\% significance level). A significant difference was observed for some formulas for Ca (B1, B2, C1, C2, $\mathrm{D} 2, \mathrm{E} 1$, and $\mathrm{E} 2), \mathrm{Cu}(\mathrm{A} 1, \mathrm{~A} 2, \mathrm{~B} 1, \mathrm{C} 2, \mathrm{D} 2$, and E2), Fe (A2, B2, C1, C2, D1, D2, E1, and E2), K (A1, C1, D2, $\mathrm{E} 1$, and $\mathrm{E} 2), \mathrm{Mg}(\mathrm{A} 2, \mathrm{~B} 2, \mathrm{C} 2, \mathrm{D} 1, \mathrm{D} 2, \mathrm{E} 1$, and $\mathrm{E} 2)$, $\mathrm{Na}(\mathrm{C} 1, \mathrm{C} 2$, D1, and D2), and Zn (B2, C1, C2, D1, D2,
E1, and E2). For Mn, all formulas presented labeled values different from experimental data obtained. The starting formulas showed better results than follow-up formulas regarding the comparison of obtained results with labeled values as well as the producers A and B in relation to the other ones. The formula D2 showed all values in disagreement with the label.

To evaluate if the obtained values were in agreement with those recommended for formulas, the obtained results were compared with international and Brazilian standards (Tables 4 and 5). For proper comparison, the elemental levels in all of the evaluated powder formulas were converted to micrograms or milligrams per 100 kcal using the specified feeding tables supplied by the infant formula manufacturers. Experimental results 
Table 4. Content of $\mathrm{Ca}, \mathrm{Cu}, \mathrm{Fe}, \mathrm{K}, \mathrm{Mg}, \mathrm{Mn}, \mathrm{Na}$ and $\mathrm{Zn}(\mathrm{mg} / 100 \mathrm{kcal})$ in starting formulas (mean $\pm \mathrm{SD}$ ) and recommended values

\begin{tabular}{|c|c|c|c|c|c|c|c|c|c|c|c|}
\hline \multirow[b]{2}{*}{ Element } & \multicolumn{5}{|c|}{ Formula } & \multicolumn{3}{|c|}{ Codex $^{1}$} & \multicolumn{3}{|c|}{ Brazil } \\
\hline & A1 & B1 & $\mathrm{C} 1$ & D1 & E1 & Minimum & Maximum & $\mathrm{GUL}^{2}$ & Minimum & Maximum & $\mathrm{GUL}^{2}$ \\
\hline $\mathrm{Ca}$ & $61.1 \pm 1.9$ & $103 \pm 3$ & $89.3 \pm 2.3$ & $83.9 \pm 3.5$ & $107 \pm 7.2$ & 50 & $\mathrm{NSP}^{3}$ & 140 & 50 & NSP & 140 \\
\hline $\mathrm{Cu}^{4}$ & $60.9 \pm 5.0$ & $61.3 \pm 2.0$ & $71.3 \pm 10.1$ & $53.9 \pm 8.9$ & $62.8 \pm 5.8$ & 35 & NSP & 120 & 35 & NSP & 120 \\
\hline $\mathrm{Fe}$ & $1.25 \pm 0.08$ & $1.33 \pm 0.08$ & $1.10 \pm 0.03$ & $1.06 \pm 0.06$ & $0.524 \pm 0.021$ & 0.45 & NSP & NSP & 0.45 & 1.3 & NSP \\
\hline K & $87.9 \pm 1.9$ & $135 \pm 4$ & $81.8 \pm 3.3$ & $89.8 \pm 6.7$ & $129 \pm 3$ & 60 & 180 & NSP & 60 & 180 & NSP \\
\hline $\mathrm{Mg}$ & $6.74 \pm 0.29$ & $8.62 \pm 0.06$ & $7.87 \pm 0.25$ & $7.58 \pm 0.08$ & $7.45 \pm 0.10$ & 5 & NSP & 15 & 5 & NSP & 15 \\
\hline $\mathrm{Mn}^{4}$ & $9.94 \pm 0.54$ & $6.79 \pm 0.10$ & $13.1 \pm 0.3$ & $11.3 \pm 0.2$ & $7.29 \pm 0.39$ & 1 & NSP & 100 & 1 & NSP & 100 \\
\hline $\mathrm{Na}$ & $23.5 \pm 1.9$ & $38.3 \pm 3.3$ & $23.1 \pm 1.4$ & $27.6 \pm 1.6$ & $26.5 \pm 1.0$ & 20 & 60 & NSP & 20 & 60 & NSP \\
\hline Zn & $0.821 \pm 0.050$ & $0.804 \pm 0.027$ & $0.535 \pm 0.029$ & $0.246 \pm 0.024$ & $0.782 \pm 0.025$ & 0.5 & NSP & 1.5 & 0.5 & NSP & 1.5 \\
\hline
\end{tabular}

${ }^{1}$ Codex $=$ Codex Alimentarius (Codex Alimentarius Commission, 2007)

${ }^{2} \mathrm{GUL}=$ guidance upper levels.

${ }^{3} \mathrm{NSP}=$ not specified.

${ }^{4}$ Results are in micrograms per $100 \mathrm{kcal}$.

Table 5. Content of $\mathrm{Ca}, \mathrm{Cu}, \mathrm{Fe}, \mathrm{K}, \mathrm{Mg}, \mathrm{Mn}, \mathrm{Na}$ and $\mathrm{Zn}(\mathrm{mg} / 100 \mathrm{kcal})$ in the analyzed follow-up infant formulas (mean value $\pm \mathrm{SD})$ and recommended values

\begin{tabular}{|c|c|c|c|c|c|c|c|c|c|c|c|}
\hline \multirow[b]{2}{*}{ Element } & \multicolumn{5}{|c|}{ Formula } & \multicolumn{3}{|c|}{ Codex $^{1}$} & \multicolumn{3}{|c|}{ Brazil } \\
\hline & $\mathrm{A} 2$ & B2 & $\mathrm{C} 2$ & D2 & E2 & Minimum & Maximum & $\mathrm{GUL}^{2}$ & Minimum & Maximum & $\mathrm{GUL}^{2}$ \\
\hline $\mathrm{Ca}$ & $128 \pm 7$ & $162 \pm 5$ & $139 \pm 4$ & $127 \pm 4$ & $108 \pm 8$ & 90 & $\mathrm{NSP}^{3}$ & NSP & 50 & NSP & 140 \\
\hline $\mathrm{Cu}^{4}$ & $98.8 \pm 5.6$ & $106 \pm 8$ & $36.1 \pm 6.8$ & $37.9 \pm 8.5$ & $96.3 \pm 4.5$ & NSP & NSP & NSP & 35 & NSP & 120 \\
\hline $\mathrm{Fe}$ & $1.50 \pm 0.02$ & $1.58 \pm 0.03$ & $1.46 \pm 0.08$ & $1.54 \pm 0.02$ & $1.66 \pm 0.03$ & 1 & 2 & NSP & 0.9 & 2.0 & NSP \\
\hline K & $141 \pm 4$ & $202 \pm 8$ & $170 \pm 3$ & $125 \pm 3$ & $141 \pm 6$ & 80 & NSP & NSP & 60 & 180 & NSP \\
\hline $\mathrm{Mg}$ & $9.21 \pm 0.12$ & $13.0 \pm 0.1$ & $13.1 \pm 0.2$ & $9.54 \pm 0.06$ & $7.47 \pm 0.08$ & 6 & NSP & NSP & 5 & NSP & 15 \\
\hline $\mathrm{Mn}^{4}$ & $7.07 \pm 0.27$ & $6.92 \pm 0.19$ & $11.1 \pm 0.2$ & $12.6 \pm 0.4$ & $10.1 \pm 0.2$ & NSP & NSP & NSP & 1 & NSP & 100 \\
\hline $\mathrm{Na}$ & $39.4 \pm 3.5$ & $58.6 \pm 1.9$ & $49.7 \pm 1.3$ & $43.3 \pm 1.4$ & $28.8 \pm 1.8$ & 20 & 85 & NSP & 20 & 60 & NSP \\
\hline $\mathrm{Zn}$ & $1.11 \pm 0.07$ & $1.26 \pm 0.07$ & $0.488 \pm 0.022$ & $0.687 \pm 0.023$ & $0.953 \pm 0.021$ & 0.5 & NSP & NSP & 0.5 & NSP & 1.5 \\
\hline \multicolumn{12}{|c|}{${ }^{1}$ Codex $=$ Codex Alimentarius (Codex Alimentarius Commission, 1987) } \\
\hline \multicolumn{12}{|c|}{${ }^{2} \mathrm{GUL}=$ guidance upper levels. } \\
\hline \multicolumn{12}{|c|}{${ }^{3} \mathrm{NSP}=$ not specified. } \\
\hline \multicolumn{12}{|c|}{${ }^{4}$ Results are in micrograms per $100 \mathrm{kcal}}$. \\
\hline & & & & & & & & & & & \\
\hline & & & & & & & & & & & \\
\hline
\end{tabular}


regarding the starting formulas are shown in Table 4 . The amount of Fe in formula B1 (1.33 \pm 0.08$)$ was close to the limit specified in the Brazilian legislation (1.3 $\mathrm{mg} / 100 \mathrm{kcal})$. The mineral content was in accordance with levels established by the Codex (Codex Alimentarius Commission, 2007) and Brazilian standards, and only 1 brand had a level of zinc (sample D1; $0.246 \pm$ $0.024 \mathrm{mg} / 100 \mathrm{kcal})$ that was not in accordance with both standards $(0.5 \mathrm{mg} / 100 \mathrm{kcal}$; Ministry of Health, National Health Surveillance Agency, 2011a). Similar behavior was observed by De Castro et al. (2010) for infant formulas in Brazil in which Zn levels were less than the minimum recommended by both standards; if only the Codex minimum values were considered for $\mathrm{Ca}$, the same formula contained levels lower than the recommended value. By contrast, Winiarska-Mieczan and Tupaj (2009) determined Ca values in Polish infant formulas that were higher than the limits of the Codex.

As shown in Table 5, for follow-up infant formulas, the Codex and Brazilian standards differ in the limits established for each element. If only the Codex is considered, 1 formulation (D1) had unsatisfactory levels of Zn (2.6\% below the minimum amount recommended), and all others would be considered suitable for consumption. However, if the Brazilian standard is used, 3 formulations would be considered unsuitable. For Ca, the levels observed in formula B2 were $15 \%$ greater than the Brazilian standard guidance upper levels, and formula C2 was very close to this limit. For K, the level in formula B2 was also greater than the Brazilian recommended maximum value $(12 \%)$, and for $\mathrm{Zn}$, the formulation $(\mathrm{C} 2)$ was below the minimum limit. It is important to mention that the $\mathrm{C} 2$ formula is supplemented with prebiotics (fructooligosaccharide and galactooligosaccharide) that stimulate the absorption of some elements, such as Ca and Zn (Scholz-Ahrens et al., 2007). Thus, the use of prebiotics could improve zinc bioavailability, and the small amount of this element may not represent a problem. However, if the same behavior is expected for $\mathrm{Ca}$, the amount of this element could exceed the maximum value recommended when supplemented with prebiotics.

\section{CONCLUSIONS}

The values obtained for the evaluated infant formulas (starting and follow-up) consumed in Brazil revealed that some are not in accordance with the Codex and Brazilian standards with respect to $\mathrm{Ca}, \mathrm{K}$, and $\mathrm{Zn}$ levels. The values declared by the producers were significantly different than the observed values, particularly for trace elements $(\mathrm{Cu}, \mathrm{Mn}$, and $\mathrm{Zn})$. Despite the limited number of sample evaluated in this work (only 1 batch of each product was used), these results dem- onstrate that further investigations about the mineral composition of infant formulas are needed. If the levels of some elements remain out of specification, special attention by the Brazilian government on the content of minerals in infant formulas will be needed. Finally, it is important to mention that no guidance upper levels have been established in the Codex Alimentarius for follow-up formulas, and the maximum value has been established for only 2 of the analyzed minerals. This lack of a standard could be a problem; as shown in the present study, if the Brazilian standard is used, several formulas could be considered out of specification.

\section{REFERENCES}

Al Khalifa, A. S., and D. Ahmad. 2010. Determination of key elements by ICP-OES in commercially available infant formulae and baby foods in Saudi Arabia. Afr. J. Food Sci. 4:464-468.

Alles, M. S., P. A. M. J. Scholtens, and J. G. Bindels. 2004. Current trends in the composition of infant milk formulas. Curr. Paediatr. 14:51-63.

Anton Paar GmbH. 2003. Multiwave 3000 Microwave Sample Preparation System Software. Version v1.27-Synt. Anton Paar GmbH, Graz, Austria.

Bermejo, P., E. Peña, R. Domínguez, A. Bermejo, J. M. Fraga, and J. A. Cocho. 2000. Speciation of iron in breast milk and infant formulas whey by size exclusion chromatography-high performance liquid chromatography and electrothermal atomic absorption spectrometry. Talanta 50:1211-1222.

Bizzi, C. A., J. S. Barin, E. E. Garcia, J. A. Nóbrega, V. L. Dressler, and E. M. M. Flores. 2011. Improvement of microwave-assisted digestion of milk powder with diluted nitric acid using oxygen as auxiliary reagent. Spectrochim. Acta B Atomic Spectrosc. 66:394-398.

Brätter, P., I. N. Blasco, V. E. Negretti de Brätter, and A. Raab. 1998. Speciation as an analytical aid in trace element research in infant nutrition. Analyst 123:821-826.

Codex Alimentarius Commission. 1987. Codex standard for follow-up formula: Codex Stan 156-1987. Accessed Sep. 23, 2012. http:// www.codexalimentarius.org/download/standards/293/CXS_156e. pdf.

Codex Alimentarius Commission. 2007. Standards for infant formulas and formulas for special medical purposes intended for infants: Codex Stan 72-1981 (Revised 2007). Accessed Sep. 23, 2012. http:// www.codexalimentarius.org/download/standards/288/CXS_072e. pdf.

De Castro, C. S. P., A. F. Arruda, L. R. Da Cunha, J. R. Souza, J. W. B. Braga, and J. G. Dórea. 2010. Toxic metals (Pb and Cd) and their respective antagonists $(\mathrm{Ca}$ and $\mathrm{Zn}$ ) in infant formulas and milk marketed in Brasilia, Brazil. Int. J. Environ. Res. Public Health 7:4062-4077.

Guo, M. R., G. M. Hendricks, P. S. Kindstedt, A. Flynn, and P. F Fox. 1996. Nitrogen and mineral distribution in infant formulae. Int. Dairy J. 6:963-979.

Hamill, T. W., E. R. Young, R. R. Eitenmiller, C. D. Hogarty, and A. M. Soliman. 1989. Ca, P, Mg, Zn, Cu, Mn, Na, K, and Cl contents of infant formulas manufactured in the United States. J. Food Compost. Anal. 2:132-139.

Hua, K. M., M. Kay, and H. E. Indyk. 2000. Nutritional element analysis in infant formulas by direct dispersion and inductively coupled plasma-optical emission spectrometry. Food Chem. 68:463-470.

Ikem, A., A. Nwankwoala, S. Odueyungbo, K. Nyavor, and N. Egiebor. 2002. Levels of 26 elements in infant formula from USA, UK, and Nigeria by microwave digestion and ICP-OES. Food Chem. 77:439-447.

Kobla, H. V., and S. L. Volpe. 2000. Chromium, exercise, and body composition. Crit. Rev. Food Sci. Nutr. 40:291-308. 
Krachler, M., and E. Rossipal. 2000. Concentrations of trace elements in extensively hydrolysed infant formulae and their estimated daily intakes. Ann. Nutr. Metab. 44:68-74.

Lesniewicz, A., A. Wroz, A. Wojcik, and W. Zyrnicki. 2010. Mineral and nutritional analysis of Polish infant formulas. J. Food Compost. Anal. 23:424-431.

MacLean, W. C., Jr., P. Van Dael, R. Clemens, J. Davies, E. Underwood, L. O'Risky, D. Rooney, and J. Schrijver. 2010. Upper levels of nutrients in infant formulas: Comparison of analytical data with the revised Codex infant formula standard. J. Food Compost. Anal. 23:44-53.

Ministry of Health, National Health Surveillance Agency. 2011a. Resolução-RDC n⿳⺈ 43, de 19 de setembro de 2011. Regulamento técnico para fórmulas infantis para lactentes. Accessed Sep. 23, 2012. http://bvsms.saude.gov.br/bvs/saudelegis/anvisa/2011/ res0043_19_09_2011.html.

Ministry of Health, National Health Surveillance Agency. 2011b. Resolução-RDC nº 44, de 19 de setembro de 2011. Regulamento técnico para fórmulas infantis de seguimento para lactentes e crianças de primeira infância. Accessed Sep. 23, 2012. http://bvsms.saude. gov.br/bvs/saudelegis/anvisa/2011/res0044_19_09_2011.html.

Richmond, J., C. D. Strehlow, and S. R. Chalkley. 1993. Dietary intake of $\mathrm{Al}, \mathrm{Ca}, \mathrm{Cu}, \mathrm{Fe}, \mathrm{Pb}$, and $\mathrm{Zn}$ in infants. Br. J. Biomed. Sci. 50:178-186.

Riva, E., E. Verduci, C. Agostoni, and M. Giovannini. 2007. Comparison of the nutritional values of follow-on formulae available in Italy. J. Int. Med. Res. 35:20-37.
Rodríguez Rodríguez, E. M., M. Sanz Alaejos, and C. Díaz Romero. 2000. Concentrations of iron, copper and zinc in human milk and powdered infant formula. Int. J. Food Sci. Nutr. 51:373-380.

Ruiz, M. C., A. Alegría, R. Barberá, R. Farré, and M. J. Lagarda. 1996. Calcium, magnesium, sodium, potassium and iron content of infant formulas and estimated daily intakes. J. Trace Elem. Med. Biol. 10:25-30.

Scholz-Ahrens, K. E., P. Ade, B. Marten, P. Weber, W. Timm, Y. Açil, C. C. Glüer, and J. Schrezenmeir. 2007. Prebiotics, probiotics, and synbiotics affect mineral absorption, bone mineral content, and bone structure. J. Nutr. 137:838S-846S

Sola-Larrañaga, C., and I. Navarro-Blasco. 2006. Preliminary chemometric study of minerals and trace elements in Spanish infant formulae. Anal. Chim. Acta 555:354-363.

Spectro Analytical Instruments GmbH \& Co. KG. 2003. Spectro Ciros CCD software version 01/March 2003. Spectro Analytical Instruments GmbH \& Co. KG, Kleve, Germany.

Taylor, L. J., M. Gallagher, and F. S. W. McCullough. 2004. The role of parental influence and additional factors in the determination of food choices for pre-school children. Int. J. Consum. Stud. $28: 337-346$.

Winiarska-Mieczan, A., and M. Tupaj. 2009. Evaluation of the mineral composition of infant formulas. J. Elementol. 14:583-591.

Zand, N., B. Z. Chowdhry, F. B. Zotor, D. S. Wray, P. Amuna, and F. S. Pullen. 2011. Essential and trace elements content of commercial infant foods in the UK. Food Chem. 128:123-128. 